12

\title{
Ламинарная обмотка тороидального поля для термоядерной электростанции типа Токамак
}

\author{
() Д.С. Дежин, Е.Ю. Клименко \\ Московский авиационный институт (национальный технически университет), \\ 125993 Москва, Россия \\ e-mail: klimenko_e@mail.ru
}

Поступило в Редакцию 2 июля 2021 г.

В окончательной редакции 2 августа 2021 г.

Принято к публикации 5 августа 2021 г.

Предложены альтернативы некоторым техническим решениям, традиционно используемым при сооружении экспериментальных термоядерных установок Токамак. Предложения позволят значительно снизить капитальные затраты на сооружение обмоток тороидального поля термоядерных электростанций этого типа за счет выбора конструкции обмотки, исключающей деградацию свойств сверхпроводящего провода, значительных упрощений конструкции провода, способа охлаждения обмотки и метода ее защиты, исключения возникновения высоких электрических напряжений. Описан метод надежного выбора рабочего тока провода и максимальных допустимых значений электрического поля в нем. Рассмотрена возможность обеспечить доступ к термоядерному узлу электростанции для регламентных работ без демонтажа обмотки тороидального поля и ее вакуумной оболочки.

Ключевые слова: термоядерная электростанция, токамак, обмотка тороидального поля, деградация, ламинарная обмотка, термосифон, гофрировка магнитного поля.

DOI: $10.21883 /$ JTF.2021.12.51768.203-21

\section{Введение}

В предвкушениаи успешного завершения миссии проекта ИТЭР термоядерное сообщество сосредоточивается на разработке концепций термоядерных электростанций (ТЯЭС) преимущественно в варианте токамака [1-4]. Обращает на себя внимание, что рассматриваемые варианты сверхпроводящих обмоток, проектируемых ТЯЭС, в значительной степени повторяют технические решения, использованные в экспериментальных токамаках. Вряд ли будет большим преувеличением утверждение о том, что новые проекты обмоток тороидального поля (ОТП) опираются скорее на разорительные традиции, чем на рациональные, менее затратные подходы, уже найденные прикладной сверхпроводимостью. В настоящей работе мы обсуждаем альтернативы нескольким традиционным технологиям.

Большая часть традиционных технологий является следствием убежденности сверхпроводящего сообщества в неизбежности деградации свойств обмоточных проводов в крупных обмотках сверхпроводящих магнитов. Явление деградации заключается в том, что в таких обмотках не удается достигнуть рабочих токов, равных критическим токам образцов провода, измеренным в магнитном поле, соответствующем максимальному расчетному полю обмотки. Не вызывает сомнений [5], что причина преждевременных переходов обмоток заключается в возникающих в обмотках механотермических возмущениях, тем более интенсивных, чем больше энергоемкость обмотки и действующие в ней силы. Несмотря на многочисленные попытки разобраться в природе этих возмущений, никаких способов оценки их амплитуды предложено не было. Наиболее глубоким, но далеко не конкретным результатом является утверждение [6], что причина заключается в особенностях прерывистой деформации обмотки. Так или иначе, сообщество смирилось с существованием этих возмущений и непредсказуемостью их амплитуды и поэтому освоило недешевый суррогатный способ [7] частичного преодоления их последствий за счет увеличения в проводе количества сверхпроводника. В таком проводе критический ток кратно превышает его расчетный рабочий ток. Делается это в надежде на то, что достигаемый таким образом температурный запас позволит проводу поглотить энергию локального возмущения, не повысив температуру до критического значения. Недостаток этого способа заключается в том, что при каждом новом шаге в сторону увеличения энергоемкости обмотки или изменения условий ее деформации в успехе его применения можно убедиться только после испытаний изготовленной полномасштабной обмотки.

Одним из разорительных последствий описанного смирения оказывается выбор способа защиты крупных сверхпроводящих обмоток, напоминающий способ защиты атомного реактора при нештатных ситуациях сбрасыванием поглощающих нейтроны стержней. Этот способ заключается в постоянной готовности вывести ток из обмотки при непредсказуемом возникновении в ней нормальной зоны. Параметры этого процесса описывается известным [5] соотношением

$$
j_{0}^{2}=\frac{I_{0} V_{\max } U(T)}{W} .
$$


Здесь $j_{0}-$ допустимая плотность тока в медной матрице провода, $I_{0}-$ номинальный ток, $V_{\max }-$ максимальное напряжение при выводе энергии, $U(T)$ функция, описывающая материал провода и зависящая от допустимой температуры локального перегрева провода, $W$ - энергоемкость обмотки. По мере увеличения энергоемкости приходится увеличивать начальную мощность вывода энергии. Проектные значения рабочего тока ОТП ИТЭР (68 kA) и напряжения $(20 \mathrm{kV})$ уже кажутся чрезмерно большими. Выбирая для ТЯЭС или для серьезного экспериментального устройства такую обмотку, работающую на грани риска, надо очень сильно надеяться на удачу.

Следующий, почти неизбежный в описываемой логике шаг - выбор непростого циркуляционного метода охлаждения сверхпроводящего провода. Метод позволяет надежно изолировать провод снаружи, чтобы он мог выдержать описанный выше акт защиты обмотки. Сверхпроводник же при этом непосредственно охлаждается потоком жидкого гелия. Несмотря на кажущуюся безальтернативность выбора, несколько критических замечаний не будут лишними. Прямой контакт сверхпроводника с жидким гелием казался необходимым в 1968 г., когда обсуждаемый метод был предложен, поскольку тогда все были увлечены изобретенным Стекли принципом стационарной стабилизации [5]. Однако в ОТП ИТЭР в длинных каналах провода используется сверхкритический гелий, не имеющий скрытой теплоты испарения и не обладающий способностью стабилизировать температуру. Организация потока гелия в канале малого сечения и километровой длины - весьма сложная задача. Сжимаемость гелия приводит к дополнительным тепловым возмущениям. И, наконец, изоляция провода не избавляет от необходимости высоковольтных изоляционных развязок между проводом и криогенной системой.

Еще одна не малая статья расходов любого нового проекта связана с формулированием повышенных требований к характеристикам сверхпроводящей проволоки. Требования включают в себя повышение критического тока сверхпроводящей проволоки при максимальной крутизне ее переходной характеристики. Первое из них обосновано стремлением сократить чрезмерный расход сверхпроводника, нужный для осуществления описанного выше суррогатного способа ослабления деградации. Второе требование выдает неосведомленность конструктора в той давно известной закономерности [8], что повышение крутизны перехода катастрофически сказывается на стабильности проволоки. Выполнение обоих требований существенно повышает стоимость провода.

\section{1. Альтернативы}

Одним из досадных следствий непротивления сообщества явлению деградации явилась традиция приступать к сооружению крупных установок, руководствуясь смутными умозрительными идеями. Примерами таких отчаянных решений могут служить токамаки Т-7, Т-15 и ИТЭР. Изложенные ниже альтернативы (по одной на каждую из перечисленных выше разорительных статей расходов) основаны на убеждении, что явление деградации отнюдь не фатально, и, более того, давно преодолено. Их применение позволит прикладной сверхпроводимости, по нашим представлениям, избавиться от авантюрного привкуса и превратиться в традиционную техническую науку, допускающую детальные расчеты, адекватные эксперименты, представительное моделирование и надежные нетривиальные конструкторские решения.

\section{1. Преодолимость деградации}

Еще в восьмидесятые годы прошлого столетия преимущественно умозрительные представления о структурной анизотропии сверхпроводящих обмоток, при деформации которых неизбежно выделение тепла из-за взаимного проскальзывания слоев или витков, привели к выводу о необходимости исключения механического взаимодействия этих элементов обмотки и недопустимости использования сверхпроводящего провода для обеспечения прочности крупных обмоток. Из этого вывода с неизбежностью возникла необходимость прочного и жесткого каркаса, на котором должен был фиксироваться сверхпроводящий провод. Для плоских обмоток произвольной формы оптимальным каркасом оказались листы из нержавеющей стали, сплава АМг6 или из стеклотекстолита благодаря их жесткости к изгибу моментами, перпендикулярными плоскости листа. Такие обмотки теперь называют ламинарными. Оптимальным способом фиксации обмотки на листе оказалась приклейка прочными компаундами, в частности, пленочным клеем ВК-36 [9]. Прочность такой склейки на сдвиг достигает $100 \mathrm{MPa}$ при температуре $4.2 \mathrm{~K}$, что многократно превышает действующие на одиночный провод сдвиговые напряжения. Кроме гарантии жесткости и прочности обмотки, металлические или композитные листы за счет своей теплопроводности обеспечивают однородную рабочую температуру всего провода. Их можно использовать для защиты обмотки методом однородного рассеяния запасенной энергии во всей обмотке, переведенной в нормальное состояние, и ее структуре. Переход обмотки однороден, поскольку при достаточно быстром уменьшении магнитного поля вихревые токи одновременно разогревают все листы, обладающие достаточной электропроводностью. В начале девяностых годов в Курчатовском институте были изготовлены несколько ламинарных обмоток экспериментального и коммерческого [10-12] назначения. Их рабочие токи были близки к критическому току образцов использованных проводов. В дальнейшем ламинарные обмотки неоднократно использовались в проектах крупных сверхпроводящих магнитов. Проекты, к сожалению, не были реализованы. 
Важная особенность ламинарных обмоток заключается в полном отсутствии возмущений механического происхождения. Если в обмотке использован сверхпроводящий провод с несколько размытым переходом, то при медленном, но практически приемлемом темпе изменения тока в нем не происходят скачки магнитного потока и нет связанных с ними тепловыделений. В $[8,13]$ описано поведение крупного по тем временам соленоида из провода с параллельными ниобий-оловянными проволоками с размытым сверхпроводящим переходом. В этом соленоиде был реализован критический ток короткого образца, а переходу соленоида в нормальное состояние предшествовало легко регистрируемое напряжение, что позволяло, несколько уменьшив ток, вернуть обмотку в сверхпроводящее состояние. Таким образом, нет никаких сомнений, что сверхпроводящие обмотки могут быть надежно рассчитаны и могут работать без риска случайного перехода в нормальное состояние.

\section{2. Выбор способа защиты ОТП}

Исключение деградации кардинально меняет требование к защите обмотки. Защита нужна только на случай форс-мажорных обстоятельств, таких, как, например, потеря вакуума в теплоизолирующей оболочке. В этом случае совсем не обязательно ограничивать разогрев обмотки быстрым выводом запасенной энергии на внешнюю нагрузку. Вполне приемлемым способом защиты является рассеяние запасенной энергии в силовой структуре обмотки с повышением ее температуры до $70-100 \mathrm{~K}$. Электрические напряжения при этом будут значительно ниже. В некоторых случаях оказывается полезным затравочное ускорение уменьшения тока. Для возбуждения вихревых токов в структуре магнита с этой целью можно использовать систему с выводом тока на разрядное сопротивление при мощности, однако, по крайней мере на три-четыре порядка ниже применяемой в ИТЭР. Использование этого метода защиты устраняет ряд проблем, связанных с обеспечением высокой электрической прочности ОТП.

\section{3. Выбор способа охлаждения обмотки}

Отсутствие опасности электрического пробоя позволяет отказаться от излишне сложного метода организации циркуляции гелия в проводе. Вполне реализуем косвенный метод охлаждения обмотки, при котором провод приклеен к подложке с достаточно высокой теплопроводностью, а подложка охлаждается жидким гелием, протекающим по приклеенным к подложке коротким каналам, независимым от провода. Косвенный метод охлаждения сверхпроводящих обмоток обладает существенными преимуществами перед двумя другими традиционными методами: погружением обмотки в ванну с жидким гелием и циркуляционным. Признанным недостатком первого из этих методов является необходимость чрезмерного количества жидкого гелия и опас- ность взрыва при его быстром испарении. Недостатки второго метода описаны выше. Если в обмотке происходят локальные импульсные возмущения, то в описанном варианте косвенного метода процесс отвода тепла двумерен и линеен, поскольку отсутствуют процессы, аналогичные кризису кипения гелия. Современное состояние прикладной сверхпроводимости позволяет полностью исключить импульсное выделение тепла в обмотке, если возникающие при изменении магнитного поля электрические поля не превышают нескольких $\mathrm{mV} / \mathrm{m}$. Косвенный метод при этом идеально стабилизирует рабочую температуру обмотки на уровне $4.2 \mathrm{~K}$. Использование в сверхпроводящих обмотках изоляции из препрега с внедренными в него сапфировыми волокнами дает редкий шанс на совмещение в одном материале высокой теплопроводности с хорошими изолирующими свойствами. Будет непростительным упущением для отечественной прикладной сверхпроводимости, если она не воспользуется для разработки такого материала отечественной недорогой технологией изготовления сапфировых волокон [14], теплопроводность которых при низких температурах значительно превосходит теплопроводность меди. В таком случае теплопроводящая подложка совмещала бы в себе функцию корпусной изоляции.

Наилучшим методом организации циркуляции жидкого гелия в коротких каналах, по нашему мнению, является термосифон. В этом методе жидкий гелий, находящийся при атмосферном давлении и имеющий поэтому температуру $4.2 \mathrm{~K}$, поступает в вертикальную петлю из находящегося над ОТП питателя, представляющего собой сосуд для хранения жидкого гелия. Длина петли равна удвоенной высоте катушки ОТП. Особенность питателя в том, что в нисходящую теплоизолированную ветвь петли гелий поступает со дна сосуда. Восходящая ветвь имеет тепловой контакт с катушкой ОТП. За счет теплопритоков к катушке жидкий гелий в восходящей петле становится парожидкостной смесью, плотность которой заметно ниже плотности жидкого гелия в нисходящей ветви. Благодаря этой разнице в термосифоне возникает самопроизвольная циркуляция. Из восходящей ветви смесь поступает в верхнюю часть питателя. После сепарации пар уходит в газгольдер, а жидкость пополняет запас гелия в питателе. Сечение термосифона выбирается таким, чтобы в смеси оставалась заметная доля жидкого гелия, обеспечивающего охлаждение катушки по всей высоте.

\section{4. Расчет провода}

Конструктор деградирующих обмоток мог обходиться такой некорректной характеристикой сверхпроводящего провода, как „критический ток“, соответствующий возникновению в образце некоторого договорного значения электрического поля. Этот ток все равно не достигался в обмотке. Конструктору ламинарных обмоток требуется значительно более точная характеристика сверх- 
проводника, а именно зависимость его проводимости от температуры, магнитного поля и плотности тока. Такое описание сверхпроводящих проводов и теория их стабильности были развиты [8] в восьмидесятые годы прошлого столетия, но не использовались большинством разработчиков сверхпроводящих обмоток по названной выше причине. Не вдаваясь в подробности, опишем лишь новые возможности, предоставляемые уточненным подходом к конструированию проводов.

В качестве модельного приближенного описания характеристик, как предполагалось, типичного технического сверхпроводника было предложено следующее выражение:

$$
\sigma(T, B, I)=\sigma_{n}\left\{1+\exp \left[\left(1-\frac{T}{T_{c}}-\frac{B}{B_{c 2}}-\frac{I}{I_{c / 2}}\right) \frac{1}{\delta}\right]\right\} .
$$

Здесь $\sigma$ - эффективная проводимость сверхпроводника, $\sigma_{n}$ - его проводимость в нормальном состоянии, $T, B, I-$ текущие значения температуры, индукции и тока, $T_{c}, B_{c 2}, I_{c / 2}$ - значения, соответствующие удвоенной величине нормальной проводимости провода, $\delta$ - параметр, описывающий крутизну сверхпроводящего перехода. Критическая поверхность, соответствующая единому критерию достижения половины нормального сопротивления, описывается уравнением плоскости, получающимся приравниванием нулю показателя экспоненты. Любым другим эффективным сопротивлениям соответствуют плоскости, лежащие под или над критической поверхностью. Оказалось, что сверхпроводники ниобий-титан и ниобий-цирконий хорошо описываются этим выражением [15], причем отклонение от линейной критической поверхности в малых полях обусловлено не отступлением от описания (1), а анизотропией пиннинга в круглой проволоке, связанной с характером деформации проволоки при ее волочении [16]. Выражение (1) применимо и к композитной, однородной по длине проволоке, если вместо нормальной проводимости сверхпроводника $\left(\sigma_{n}\right)$ использовать проводимость $\left(\sigma_{m}\right)$ композитного провода в нормальном состоянии. Нетрудно убедиться, что относительная величина критических характеристик композитного провода снижена на $\delta \ln \left(\sigma_{m} / \sigma_{n}\right)$ по сравнению с характеристиками сверхпроводника.

К сожалению, запланированное исследование критической поверхности ниобий-олова не было проведено как из-за ВТСП ажиотажа, охватившего сообщество после 1986 года, так и из-за необходимости изготовления специального образца с однородными по длине свойствами, что представляет непростую для этого материала задачу. Вопрос о таких исследованиях ВТСП материалов до сих пор даже не ставился. Хотелось бы думать, что выражение (1) является фундаментальным для любого сверхпроводящего провода, а форма критической поверхности может оказаться неплоской вследствие конечного числа факторов, поддающихся расчету. Пока оснований для такого заключения недостаточно. Тем не менее мы воспользуемся выражением (1) для демонстрации принципа конструирования ниобий-оловянной проволоки. Поскольку технический интерес представляют эффективные проводимости, значительно превышающие проводимость в нормальном состоянии, можно пренебречь в выражении (1) единицей по сравнению с большим экспоненциальным членом, что заметно упростит анализ. Вольт-амперную характеристику в безразмерных параметрах с учетом разогрева провода собственным током можно получить из несложного уравнения

$$
-\delta^{*} \ln \frac{\varepsilon}{i}=1-\alpha \varepsilon i-i
$$

где

$$
\begin{gathered}
\varepsilon=\frac{R(T, B) I}{R_{n} I_{c / 2}}, \quad i=\frac{I}{I_{c / 2}}, \quad \alpha=\frac{R_{n} I_{c / 2}^{2}}{\lambda T^{*}}, \\
\delta^{*}=\frac{\delta}{1-b}, \quad b=\frac{B}{B_{c 2}}, \quad \lambda T^{*}
\end{gathered}
$$

- поток тепла от провода к подложке через слой электрической изоляции. $T^{*}-$ превышение температурой образца температуры охлаждающей подложки. Уравнение (2) легко решается параметрически [8].

Примеры вольт-амперных характеристик, соответствующих различным $\delta$ при постоянном значении $\alpha$ и наоборот, приведены на рис. 1. Все они имеют устойчивый участок вплоть до точки, в которой $\frac{d i}{d \varepsilon}=0$. Этой точке соответствует максимально достижимый ток, зависящий от $\delta$ и от $\alpha$. Из этих рисунков видно, что для сверхпроводящего провода, качество которого описывается параметрами $I_{c / 2}$ и $\delta$, можно подобрать такое значение $\alpha$, чтобы провод сохранял устойчивость вплоть до некоторого, выбираемого конструктором уровня допустимого электрического поля, причем максимальный уровень такого поля тем больше, чем больше размытость сверхпроводящего перехода. Выбираемый конструктором уровень электрического поля определяется желаемой скоростью изменения тока в обмотке, возможностью регистрации сигнала о приближении к предельно допустимому значению тока, а также величиной внешних электрических полей, если такие поля возникают в процессе эксплуатации обмотки. Чтобы конструктор имел возможность такого выбора, нужно, с одной стороны, пересмотреть методику оценки качества провода и определять не условный „критический ток“, а величины $\left(I_{c / 2}\right.$ и $\left.\delta\right)$, пригодные для расчетов. С другой стороны при производстве сверхпроводящей проволоки следует стремиться не к максимальной крутизне сверхпроводящего перехода, а к достижению задаваемого заказчиком уровня $\delta$.

В настоящей работе мы не ставим задачу глобальной оптимизации проводов. Приведем лишь один пример расчета параметров стренда транспонированного провода типа кабеля Рёбеля для ОТП ТЯЭС в магнитном поле $16 \mathrm{~T}$. Возможность выбора такой величины максимального магнитного поля обеспечил прогресс в технологии изготовления ниобий-оловянного провода в 

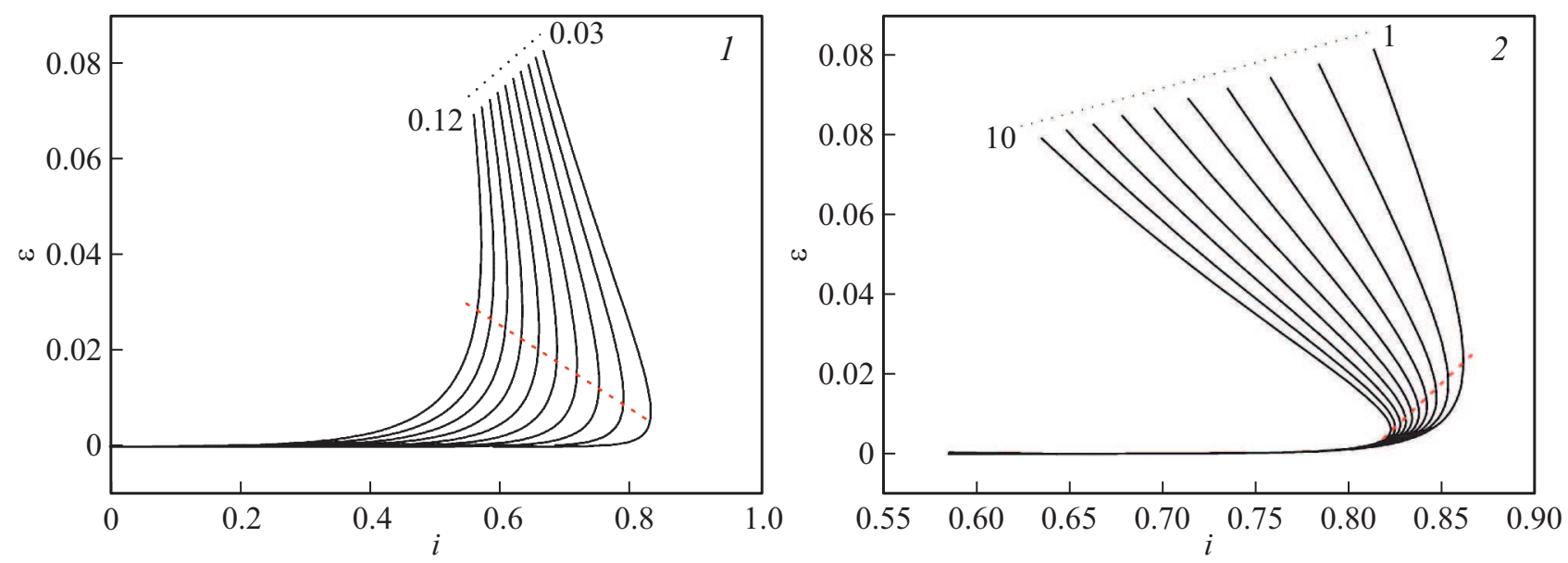

Рис. 1. Вольт-амперные характеристики образцов в зависимости от $\delta$ и $\alpha: 1-\alpha=5.0, \delta=0.12-0.03$ с шагом $-0.01 ; 2-$ $\delta=0.03, \alpha=10-1$ с шагом -1.0 .

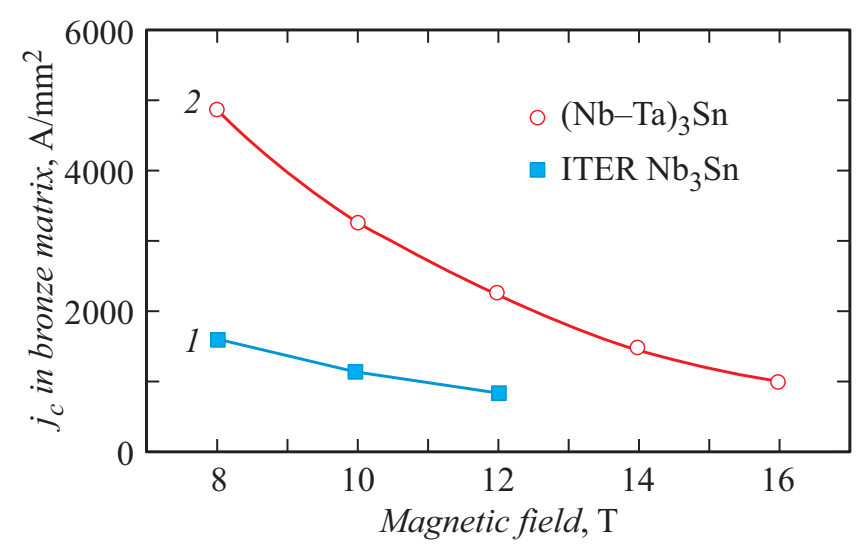

Рис. 2. Сопоставление характеристик ниобий-оловянных проводов в бронзовой матрице, разработанных в 2000 [17] и 2018 [18] годах.

бронзовой матрице со времен выпуска проволок для ИТЭР (рис. 2). Известны ниобий-оловянные проволоки с еще большей токонесущей способностью за счет использования в волокнах дополнительных источников олова. Однако хрупкость таких проволок заставляет ждать результатов их испытаний в магнитах ускорителей, конструкторы которых предъявили к технологам столь завышенные требования.

Для расчета провода нужно знать величину $I_{c / 2}$. Определить ее по результатам измерения критического тока на уровне условного электрического поля не удается. Для демонстрации методики условимся, что критическому току на рис. 2 соответствовала величина $i=0.7$ и тогда для проволоки с сечением бронзы $1 \mathrm{~mm}^{2}$ $I_{c / 2}=1400 \mathrm{~A}$ в магнитном поле $16 \mathrm{~T}$. Такому проводу в обмотке при $\alpha=3$ и $\delta=0.03$ соответствует максимальный ток 1240 А и электрическое поле $1.3 \mathrm{mV} / \mathrm{m}$, сечение меди в проводе $3.12 \mathrm{~mm}^{2}$ и мощность тепловыделения $1.6 \mathrm{~W} / \mathrm{m}$. В рабочем режиме мощность генерации тепла должна быть раз в 1000 меньше, т.е. рабочий ток должен быть 950 А, т.е. ниже максимального тока на $\delta I_{c / 2} \ln 1000=290$ А. Сечение стренда с учетом сверхпроводника $\left(1 \mathrm{~mm}^{2}\right)-2 \times 2.06 \mathrm{~mm}$.

\section{5. Конструкция обмотки}

Ламинарные катушки ОТП могут представлять собой набор из 30 слоев по 30 витков в каждом, фрагмент обмотки изображен на рис. 3. Жесткие корпуса не потребуются из-за ослабления взаимодействия ОТП с полоидальными полями катушек, размещенных внутри ОТП. Впрочем, и в случае ИТЭР охлаждаемую массу катушек можно было бы заметно уменьшить, передав так называемые валящие моменты на внешнюю теплую оболочку установки. Изменение метода защиты обмотки отменяет требование чрезмерно большого рабочего тока обмотки. Едва ли не единственным основанием для выбора этой величины остается технологичность обмотки.

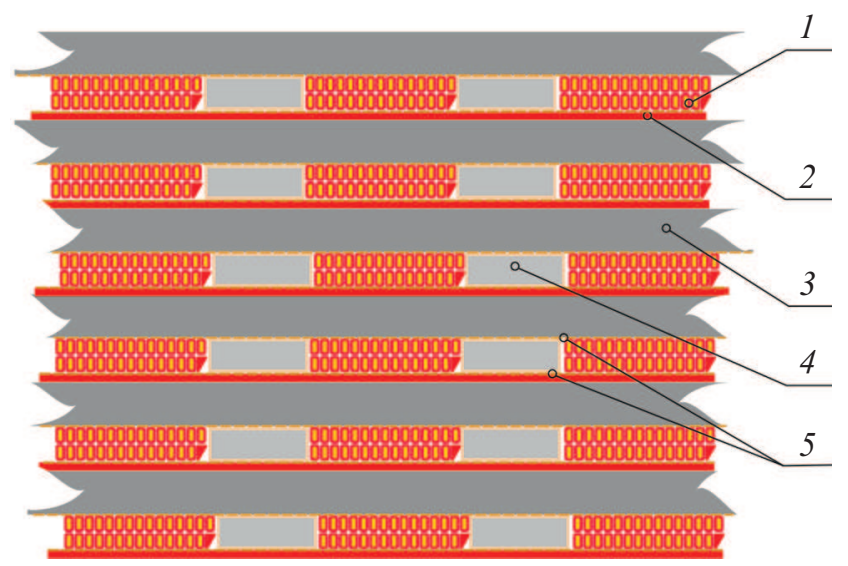

Рис. 3. Фрагмент сечения ламинарной обмотки $A-A$ (см. рис. 4): 1 - обмоточный провод, 2 - хладопровод, 3 - силовая пластина, 4 - распорный элемент, 5 - изоляция (препрег). 
По нашим представлениям, рабочий ток должен находиться в интервале 20-30 kA. Наиболее дешевым вариантом такого провода может быть полностью транспонированный провод прямоугольного сечения $(4.2 \times 30 \mathrm{~mm})$. Такой провод с рабочим током $25 \mathrm{kA}$ состоит из 29 проволок (стрендов) прямоугольного сечения $(2 \times 2.06 \mathrm{~mm}$, соотношение сечений медь/бронза равно 1.06).

Для получения на обмотке $16 \mathrm{~T}$ потребуется около 900 витков в каждой из 10 катушек. Ширина катушки выбирается так, чтобы их обмотки, сомкнувшись на опорном цилиндре, образовали сплошной однородный токовый слой. При диаметре опорного цилиндра $5 \mathrm{~m}$ ширина катушки составит $1570 \mathrm{~mm}$. Толщина силовых пластин $(t)$ может оказаться довольно большой, поскольку растягивающее усилие в $D$-образной катушке может быть порядка 1 GN. По нашим представлениям, силовую пластину и распорный элемент целесообразно изготавливать намоткой холоднокатаной лентой, имея в виду как повышенную прочность проката, так и упрощение технологии очень крупных катушек. Невысокие электрические напряжения позволяют изолировать силовые пластины и распорные элементы препрегом толщиной $0.3 \mathrm{~mm}$. Обмоточный провод используется без изоляции. В случае $D$-образной катушки прочность контакта провода с силовой пластиной с большим запасом обеспечивается современными связующими, совпадающими по составу, например, с пленочным клеем ВК-36. В случае упомянутого ниже варианта обмотки с вертикальными силовыми пластинами сдвиговые напряжения существенно больше, но современные компаунды и для такой конструкции обеспечивают прочность фиксации обмоточного провода на пластине с большим запасом.

\section{6. Компоновка ОТП}

Важным отличием ОТП термоядерной электростанции от экспериментальных токамаков должна быть возможность доступа к термоядерному узлу без нарушения работоспособности этой обмотки. Для этого неизбежно придется ограничить число катушек в ОТП и существенно увеличить их горизонтальный размер так, чтобы роботы достаточной грузоподъемности могли проникнуть к термоядерному узлу для проведения регламентных работ. Внешний обвод каждой катушки должен быть заключен в свою теплоизолирующую оболочку, соединенную с центральной оболочкой, вмещающей внутренние части ОТП, опорный цилиндр и центральный соленоид. Внутренние части катушек, расположенные вокруг опорного цилиндра, образуют непрерывный по азимуту токовый слой с однородной плотностью тока. Это позволяет избежать гофрировки тороидального магнитного поля и образования локальных плазменных ловушек. Влияние внешнего обвода будет незначительным из-за удаленности от плазменного шнура. Например, гофрировка поля от десяти катушек шириной $1.57 \mathrm{~m}$ при горизонтальном размере $16 \mathrm{~m}$ составит на внутреннем

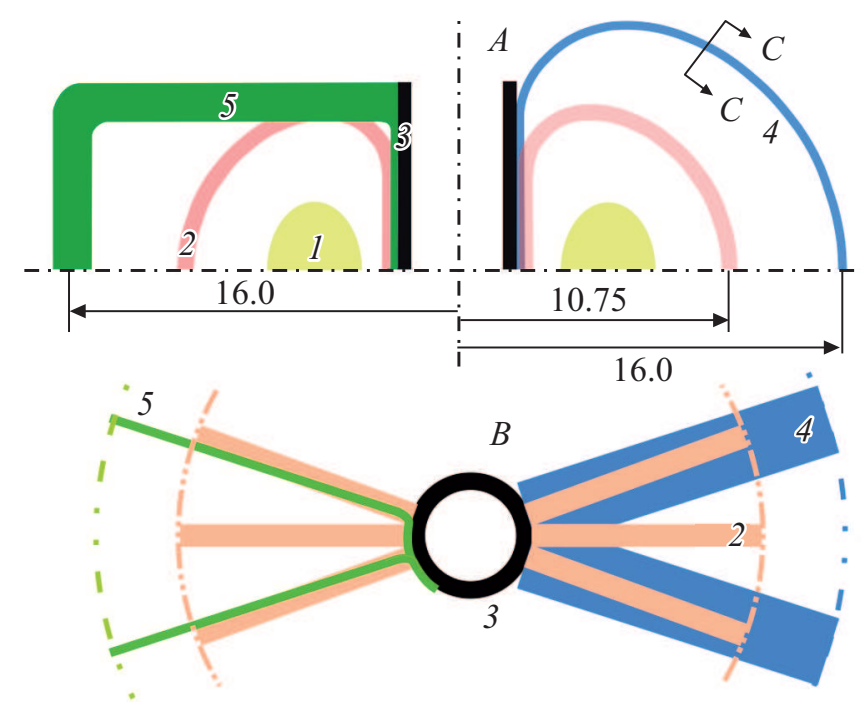

Рис. 4. Варианты компоновки ОТП ТЯЭС в сравнении с ОТП ИТЭР; $A-$ фронтальный разрез, $B-$ вид сверху (указаны по 2 из 10 катушек ОТП ТЯЭС и по 3 из 18 катушек ИТЭР). 1 - плазма, 2 - ОТП ИТЭР, 3 - опорный цилиндр, 4 - катушка ОТП ТЯЭС со слоями, расположенными по обходу контура катушки, 5 - катушка ОТП ТЯЭС с вертикальными слоями.

(4.2 m), среднем (6.2 m) и наружном (8.2 m) диаметрах плазмы соответственно 0.0197, 0.00095 и 0.139\%. Для сравнения - у ИТЭР гофрировка несколько больше и составляет соответственно $0.08066,0.008505$ и $1.15 \%$.

Появление свободного пространства внутри ОТП позволит разместить там не чувствительное к магнитному полю оборудование, а на этапе монтажа оснастку для изготовления полоидальных катушек, расположенных максимально близко к плазме. На схеме (рис. 4) изображены два варианта ОТП ТЯЭС в сопоставлении с размерами ОТП ИТЭР. Возможно, вариант с вертикальными силовыми пластинами окажется более экономичным, если жесткость силовых пластин шириной 1.6-2 $\mathrm{m}$ будет достаточной для восприятия изгибающих моментов при выборе формы обмотки, отличной от $D$-образной.

Использование традиционного арочного распора для удержания сил, стягивающих катушки к оси тороида, для описанных ламинарных обмоток кажется разрешаемой, но не простой задачей. Применение для этой цели опорного цилиндра - более простой выход. На рис. 5 и 6 приведены результаты численной оценки запаса прочности и деформаций опорного цилиндра, состоящего из двух вложенных друг в друга оболочек из стали AISI 4340 (предел прочности $745 \mathrm{MPa}$, предел текучести $470 \mathrm{MPa}$ ). Толщина опорного цилиндра $500 \mathrm{~mm}$, внешнее давление, направленное по радиусу, $1.08 \mathrm{MPa}$. Проведенная оценка показывает, что вариант опорного цилиндра в принципе реализуем. От конструктора зависит конкретный вариант опоры катушек ОТП: сочетание опорного цилиндра и арочного распора, сочетание опорного цилиндра и центрального соленоида, возмож- 
Surface: von Mises safety factor (1)

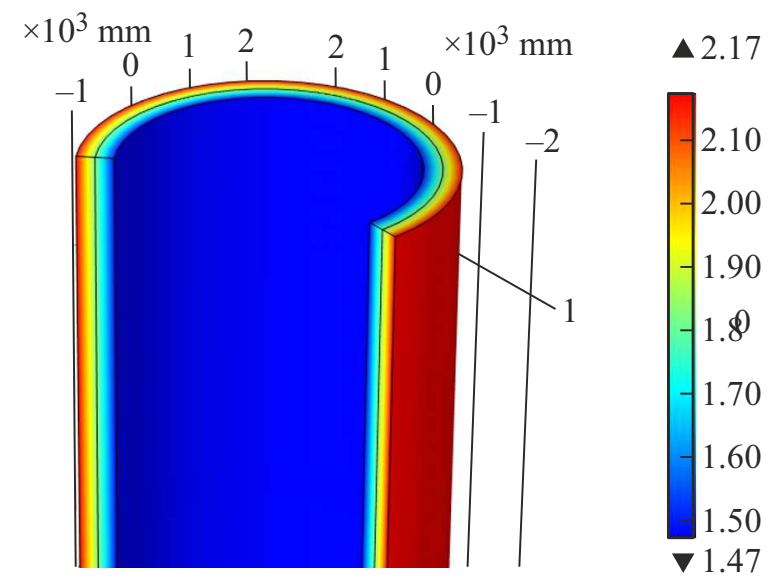

Pис. 5. Распределение запаса прочности опорного цилиндра по фон Мизесу.

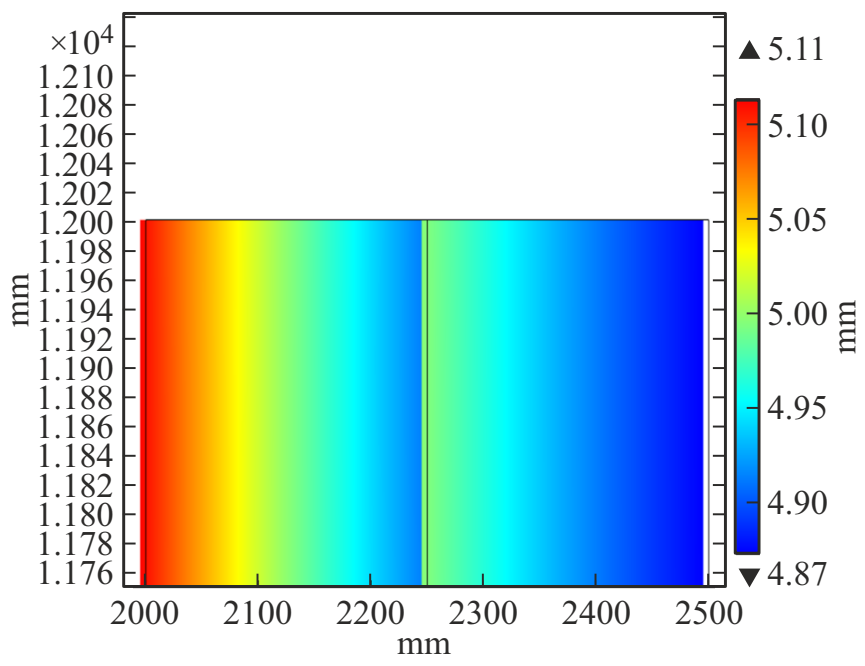

Рис. 6. Карта радиальных смещений опорного цилиндра.

ная ламинарная конструкция которого описана в [19]. Опорный цилиндр не должен экранировать плазму от магнитного потока центрального соленоида. Как вариант его конструкции может быть рассмотрен цилиндр из секций, намотанных изолированной стальной лентой. Придется позаботиться об ограничении электрических напряжений, возникающих в таких секциях при изменении тока в центральном соленоиде. Представляется, что использование намотанных и склеенных конструкций одна из возможных недорогих опций технологии грандиозных сверхпроводящих обмоток для ТЯЭС.

\section{Заключение}

Сложившиеся в результате сорокалетней истории проектирования сверхпроводящих обмоток ИТЭР оценки сложности конструкции и чрезвычайно высокой стои- мости этих устройств сильно преувеличены. Современный уровень развития прикладной сверхпроводимости допускает более простые и значительно менее затратные варианты обмоток для ТЯЭС. В частности, применение ламинарных обмоток, исключающих явление деградации, устраняет чрезмерный расход сверхпроводника, а также позволяет использовать недорогой транспонированный прямоугольный провод вместо весьма трудоемкого кабеля в оболочке. Значительно упрощаются системы защиты и охлаждения обмотки. Устраняются проблемы обеспечения электрической прочности ОТП и понижается уровень рабочих температур до температуры кипения жидкого гелия при атмосферном давлении.

\section{Финансирование работы}

Исследование выполнено при финансовой поддержке проекта Российской Федерацией в лице Минобрнауки России соглашение № 075-15-2020-770.

\section{Конфоликт интересов}

Авторы заявляют, что у них нет конфликта интересов.

\section{Список литературы}

[1] G. Federici, C. Bachmann, L. Barucca, W. Biel, L. Boccaccini, R. Brown, C. Bustreo, S. Ciattaglia, F. Cismondi, M. Coleman, V. Corato, C. Day, E. Diegele, U. Fischer, T. Franke, C. Gliss, A. Ibarra, R. Kembleton, J.H. You. Fusion Engineering and Design, 136, Part A, 729 (2018).

[2] A.J. Creely, M.J. Greenwald, S.B. Ballinger, D. Brunner, J. Canik, J. Doody, T. Fulop, D.T. Garnier, R. Granetz, T.K. Gray, C. Holland, N.T. Howard, J.W. Hughes, J.H. Irby, V.A. Izzo, G.J. Kramer, A.Q. Kuang, B. LaBombard, Lin Yijun, B. Lipschultz, N.C. Logan, J.D. Lore, E.S. Marmar, K. Montes, R.T. Mumgaard, C. Paz-Soldan, C. Rea, M.L. Reinke, P. Rodriguez-Fernandez, K. Sarkimaki, F. Sciortino, S.D. Scott, A. Snicker, P.B. Snyder, B.N. Sorbom, R. Sweeney, R.A. Tinguely, E.A. Tolman, M. Umansky, O. Vallhagen, J. Varje, D.G. Whyte, J.C. Wright, S.J. Wukitch, J. Zhu. J. Plasma Phys., 86, 865860502 (2020).

[3] Hua Li, Ge Li, Lu Qu, Peng Fu. J. Fusion Energy, 33, 613 (2014).

[4] S. Entler, J. Horacek, T. Dlouhy, V. Dostal. Energy, 152, 489 (2018).

[5] M.N. Wilson Superconducting Magnets (Clarendon Press, Oxford, 1983) [М. Уилсон. Сверхпроводящие магниты (Мир, М., 1985)]

[6] А.В. Кривых. Механические и электромагнитные свойства конструкционных материалов сверхпроводниковых магнитов для установок термоядерного синтеза, Дисс. д.т.н. (М., НИЦ Курчатовский институт, 2014)

[7] С.А. Егоров Разработка сверхпроводящих магнитных систем индуктивных накопителей энергии и термоядерных установок, Автореф. д.т.н. дис. (НИИЭФА, СПб, 2006)

[8] Е.Ю. Клименко, Н.Н. Мартовецкий, С.И. Новиков, ДАН СССР, 261 (6), 1350 (1981). 
[9] „Авиационные материальс“, Справочник, том 10, „Клеи, герметики, резины, гидрожсидкости“, Часть 1 „Клеи, клеевые препреги“ (ВИАМ, М., 2019).

[10] P.A. Cheremnykh, V.R. Fedorov, E.Yu. Klimenko, V.N.Lunin, S.I. Novikov. IEEE Transactions on Magnetics, 24, 882 (1988).

[11] E.Yu. Klimenko, S.I. Novikov, V.I. Omelyanenko, S.A. Sergeev. Cryogenics, 30, 41 (1990).

[12] И.О. Анашкин. Е.Ю. Клименко, С.А. Лелехов, Н.Н. Мартовецкий, С.И. Новиков, А.А. Пехтерев, И.А. Посадский. Атомная энергия, 57, 401 (1984).

[13] N.A. Chernoplekov. MT-6 Proceedings, Bratislava, ALPHA, 3 (1977).

[14] S.T. Mileiko. Compos. Sci. Technol., 65 (15-16), 2500 (2005).

[15] Е.Ю. Клименко, А.Б. Именитов, С.В. Шавкин, П.В. Волков. ЖЭТФ, 127 (1), 56 (2005).

[16] Е.Ю. Клименко, М.С. Новиков, А.Н. Долгушин. Физика металлов и металловедение, 92 (3), 11 (2001). [E.Yu. Klimenko, M.S. Novikov, A.N. Dolgushin. The Physics of Metals and Metallography, 92 (3) 219 (2001).]

[17] G.L. Dorofejev, A.B.Imenitov, E.Yu. Klimenko. Cryogenics, 20, 307 (1980).

[18] A. Nijhuis, R.P. Pompe van Meerdervoort, H.J.G. Krooshoop, W.A.J. Wessel. University of Twente, Intermediate Report UT10-2013-3 (2013).

[19] V. Abacherli, B. Seeber, E. Walker, R. Flukiger, W. Thiele, J.A.A.J. Perenboom. IEEE Transactions on Appl. Superconduct., 11 (1), 3667 (2001).

[20] E.Yu. Klimenko, IEEE Transactions on Appl. Superconduct., 28, 420100 (2018). DOI: 10.1109/TASC.2017.2779513 